\title{
Rhinovirus is associated with severe adult community-acquired pneumonia in China
}

\author{
Keqiang Wang $^{1 *}$, Wen $\mathrm{Xi}^{1 *}$, Donghong Yang ${ }^{1 *}$, Yali Zheng ${ }^{1 *}$, Yaqiong Zhang ${ }^{2}$, Yusheng Chen ${ }^{3}$, Chunliang \\ Yan $^{4}$, Guizhen Tian ${ }^{5}$, Shuchang An ${ }^{6}$, Xiangxin $\mathrm{Li}^{7}$, Fucheng An ${ }^{8}$, Juan Du${ }^{9}, \mathrm{Ke} \mathrm{Hu}^{10}$, Jie Cao ${ }^{11}$, Lili $\operatorname{Ren}^{12}$, \\ Fang Huang ${ }^{13}$, Zhancheng Gao ${ }^{1}$
}

${ }^{1}$ Department of Respiratory and Critical Care Medicine, Peking University People's Hospital, Beijing 100044, China; ${ }^{2}$ Department of Respiratory and Critical Care Medicine, Peking University International Hospital, Beijing 102206, China; ${ }^{3}$ Department of Respiratory Medicine, Fujian Provincial Hospital, Fuzhou 350001, China; ${ }^{4}$ Department of Respiratory Medicine, Beijing Aerospace General Hospital, Beijing 100076, China; ${ }^{5}$ Department of Respiratory Medicine, 263 Hospital of the Chinese People's Liberation Army, Beijing 101149, China; ${ }^{6}$ Department of Respiratory Medicine, The First Hospital of Tsinghua University, Beijing 100016, China; ${ }^{7}$ Department of Respiratory Medicine, Beijing Changping Hospital, Beijing 102200, China; ${ }^{8}$ Department of Respiratory Medicine, Beijing Mentougou District Hospital, Beijing 102300, China; ${ }^{9}$ Department of Respiratory Medicine, The Affiliated Hospital of Guiyang Medical College, Guiyang 550004, China; ${ }^{10}$ Department of Respiratory Medicine, Renmin Hospital of Wuhan University, Wuhan 430060, China; ${ }^{11}$ Department of Respiratory Medicine, Tianjin Medical University General Hospital, Tianjin 300052, China; ${ }^{12}$ National Institute for Viral Disease Control and Prevention, China CDC, Beijing 100052, China; ${ }^{13}$ Beijing Center for Disease Prevention and Control, Beijing 100013, China

Contributions: (I) Conception and design: K Wang, W Xi, D Yang, Y Zheng, Z Gao; (II) Administrative support: Z Gao; (III) Provision of study patients: Y Chen, C Yan, G Tian, S An, X Li, F An, J Du, K Hu, Ji Cao, L Ren, F Huang; (IV) Collection and assembly of data: K Wang, W Xi; (V) Data analysis and interpretation: D Yang, Y Zheng; (VI) Manuscript writing: All authors; (VII) Final approval of manuscript: All authors.

*These authors contributed equally to this work.

Correspondence to: Zhancheng Gao, MD, PhD. Department of Respiratory and Critical Care Medicine, Peking University People’s Hospital, Beijing 100044, China. Email: zcgao@bjmu.edu.cn.

Background: Human rhinovirus (HRV) is one of the most common viral etiologies detected in community-acquired pneumonia (CAP) adult cases. However, few is known about the characteristics of HRV-associated CAP. To describe the clinical features of HRV-associated CAP in immunocompetent adults admitted to multiple medical centers in mainland China over a 2-year period.

Methods: A total of 383 patients admitted to hospitals for CAP were enrolled from 46 medical centers in mainland China between January 2013 and December 2014. Multiplex real-time polymerase chain reaction (RT-PCR) assays for viral detection and DNA-based quantitative loop-mediated isothermal amplification (qLAMP) assays for bacterial detection were implemented to all lower respiratory tract specimens obtained from the patients. Twenty-eight cases (28/383, 7.3\%) revealed HRV-positive PCR results. Patients with bronchoalveolar lavage (BAL) HRV-positive PCR results $(n=20)$ were further enrolled and divided into two groups depending on the status of bacterial co-infection (viral group, $n=12$; viral-Bacterial group, $n=8$ ). Demographic, clinical and microbiological data were reviewed and compared in detail.

Results: Cases with HRV-infection were remarkably correlated with respiratory failure (14/20) and most of them (13/14) received mechanical ventilation. Fever (17/20), productive cough (15/20) and dyspnea (6/20) were common symptoms while flu-like symptoms were rarely observed in the cohort. Streptococcus pneumoniae (3/8), Klebsiella pneumoniae (3/8) and Mycoplasma pneumoniae (2/8) were most frequently identified bacterium in the viral-bacterial group. Compared with the viral group, higher incidence of septic shock (3/8 vs. 1/12, $\mathrm{P}=0.255)$, longer ICU length of stay (LOS) (10.0 vs. 6.5 days, $\mathrm{P}=0.686)$, longer hospital LOS (18.5 vs. 13.0 days, $\mathrm{P}=0.208)$ and higher 28 -day mortality $(2 / 8$ vs. $2 / 12, \mathrm{P}=1)$ were observed in the Viral-Bacterial group, although without statistically significant difference.

Conclusions: HRV is a common etiology in CAP among China adults, especially in severe CAP. Clinicians should be vigilant considering of the poor outcome. Highly qualified multiplex PCR techniques with invasive sampling are needed to increase the detection rate.

(c) Journal of Thoracic Disease. All rights reserved. 
Keywords: Human rhinovirus (HRV); community-acquired pneumonia (CAP); immunocompetent; pathogen; bronchoalveolar lavage (BAL); loop-mediated isothermal amplification (LAMP)

Submitted Jul 30, 2017. Accepted for publication Oct 17, 2017.

doi: $10.21037 /$ jtd.2017.10.107

View this article at: http://dx.doi.org/10.21037/jtd.2017.10.107

\section{Introduction}

Community-acquired pneumonia (CAP) is a heterogeneous disease causing great mortality and morbidity and high costs worldwide. Etiologies, disease courses, and outcomes are highly variable in CAP patients. Anti-bacterial infection therapies are widely accepted as the principle therapeutic regimen for CAP. However, new molecular diagnostic assays, such as the polymerase chain reaction (PCR) tests, have increased the ability to detect respiratory viruses over the past 10 years. According to published studies, viruses account for $29-55 \%$ of CAP cases among adults (1-5) and the most common virus detected is human rhinovirus (HRV) (4.9-30.6\%) (2,3,5). Mountain reports now indicate that HRV can be an independent causative pathogen of pneumonia, even severe pneumonia (6-8). However, by now we still knew few about the characteristics of HRVassociated pneumonia, especially CAP.

The aim of this prospective study was to describe the clinical features of HRV-associated CAP in adults admitted to multiple medical centers in mainland China over a 2 -year period. HRV-infection was confirmed via positive PCR results detected in lower respiratory tract specimens obtained from CAP patients.

\section{Methods}

\section{Study subjects and design}

Our study was one part of a prospective multicenter study aimed to characterize the etiology spectrum of CAP in adults, which began on January 1, 2010, and had involved 46 medical centers in mainland China. It was approved by the Ethics Committee of Peking University People's Hospital (No. 2011-83), and written informed consents were requested from all patients or their guardians. In the current study, all adult patients (aged $>16$ years) admitted to the 46 centers between January 2013 and December 2014 with CAP were enrolled. Exclusive standards were as follows: (I) being immunocompromised, including history of glucocorticoid taken for more than 1 month, history of immunosuppressive therapy, history of human immunodeficiency virus (HIV) infection, solid tumor or hematological malignancy; (II) history of long-term nursing home stays; (III) history of recently hospitalized ( $<90$ days); (IV) finally diagnosed as noninfectious diseases.

\section{Definition}

CAP and severe CAP (SCAP) was defined according to the standard published by America/American Thoracic Society in 2007 (9). The presence of pneumonia was confirmed by a new pulmonary infiltrate in chest radiograph accompanied with one of the following criteria: (I) exacerbated cough or sputum production; (II) fever $>38.5^{\circ} \mathrm{C}$; (III) peripheral white blood cell (WBC) count $>10 \times 10^{9} / \mathrm{L}$ or $<4 \times 10^{9} / \mathrm{L}$. Image changes should be neither pre-existing nor of other known causes.

\section{Microbiological evaluation}

Lower respiratory tract specimens including sputum, endotracheal aspiration was collected during the first 24 hours after hospital admission. Bronchoalveolar lavage (BAL) samples were obtained whenever possible within 7 days after admission. The specimens were stored in sterile sample tubes, deep-frozen at $-80{ }^{\circ} \mathrm{C}$ until analyzed in a central laboratory at Peking University People's Hospital. All samples were analyzed with multiplex real-time PCR assays for viral detection and DNA-based quantitative loopmediated isothermal amplification (qLAMP) assays for bacterial detection.

\section{Viral detection}

Total viral nucleic acids were extracted from respiratory samples using a QIAamp MinElute Virus Spin Kit (Qiagen Inc., Valencia, CA, USA). The presence of HRV and other common respiratory pathogens were screened using an AgPath-ID ${ }^{\text {TM }}$ One-Step real-time polymerase chain reaction (RT-PCR) kit (Ambion) with the FTD respiratory pathogens 21 kit (Fast Track Diagnosis, Luxembourg), 
which included influenza $A / B$, influenza $A H 1 N 1$, rbinovirus, coronaviruses (NL63, 229E, OC43, and HKU1), parainfluenza viruses $[1,2,3,4]$, buman metapneumovirus $A / B$, bocavirus, respiratory syncytial virus $A / B$, adenovirus, parechovirus, and enterovirus. A virus was considered as the etiology of CAP when the $\mathrm{Ct}$ value was $<30$, using GAPDH as an internal control (10).

\section{Bacterial detection}

Loop-mediated isothermal amplification (LAMP) assays were used to detect 13 common bacterial pathogens of CAP, including Streptococcus pneumoniae, Staphylococcus aureus, Methicillin-resistant Staphylococcus aureus, Escherichia coli, Klebsiella pneumoniae, Pseudomonas aeruginosa, Acinetobacter Baumannii, Stenotrophomonas maltophilia, Haemophilus influenza, Legionella pneumophila, Mycobacterium tuberculosis, Mycoplasma pneumoniae, and Chlamydia pneumoniae. In our previous studies, LAMP assay had been proved to be an effective technique for detection of bacteria and atypical pathogens $(11,12)$. A bacterium was considered to be the causative pathogen only if the DNA concentration was over $10^{4}$ copies $/ \mathrm{mL}$.

\section{Data collection}

Cases were enrolled when BAL revealed HRV-positive PCR results. Enrolled patients were classified into two groups as follows: the viral group, if only HRV was detected in etiological examinations; and the viral-bacterial group, if etiological examinations revealed mix viral-bacterial infection. Medical records were reviewed and compared in detail, including demographic characteristics, clinical, microbiological and radiographic data.

\section{Statistical analysis}

For continuous variables, medians with interquartile range (IQR) were used, and counts (\%) were used for categorical variables. Continuous variables and categorical variables were analyzed by the two-group's test or Fisher's exact test. A P-value of less than 0.05 was considered as statistically significant. All data analyses were carried out with the SPSS program (Version 22.0, SPSS, Inc., Chicago, IL, USA).

\section{Results}

A total of 383 CAP patients admitted to the 46 centers were applicable for the study. The etiology of CAP was detected in lower respiratory tract specimens (including sputum, endotracheal aspiration, and BAL) in 239 cases (62.4\%), and HRV-positive results were noted in 28 cases (7.3\%). Of the 28 patients, HRV was detected in 6 sputum samples and 22 BAL fluid samples. Considering of the reliability and validity of etiology analyses, only data from the 20 BALpositive patients ( 2 cases were further excluded due to lost to follow-up) were reviewed and compared (Figure 1).

\section{Baseline characteristics}

Characteristics of the cohort were detailed in Table 1. The median age was 61.5 years old, range from 18 to 89 years. Male $(15,75 \%)$ and older patients ( $>45$ years) $(15,75 \%)$ seemed to be more susceptive to HRV-infection. Analysis of the onset time showed no obvious seasonal character, but there might be a small epidemic between April and July (the spring and summer season in the northern hemisphere) (Figure 2). Two patients had travel histories, one to the Philippines and the other to Russia, without an observed epidemic of HRV in the two regions. In the current study, most cases $(12 / 20,60 \%)$ had underlying diseases, and 3 (15\%) patients had primary pulmonary diseases. However, cases with respiratory disorders were not associated with a higher incidence of bacterial co-infection as formerly suspected. Compared with the viral-bacterial group, subjects in the viral group were older ( 66 vs. 45 years, $\mathrm{P}=0.157$ ) and had a less incidence of underlying diseases (6/12 vs. 8/12, $\mathrm{P}=0.109)$, although without a statistical significance.

\section{Medical admission data}

\section{Symptoms}

Patients' clinical characteristics on admission were depicted in Table 2. Most patients had moderate to high fever when admitted. Fever $(17 / 20,85 \%)$, productive cough (15/20, $75 \%)$, and dyspnea $(6 / 20,30 \%)$ were the most common symptoms observed in the cohort. Flu-like symptoms such as throat pain $(2 / 20,10 \%)$, headache $(1 / 20,5 \%)$ and arthralgia $(1 / 20,5 \%)$ were relatively infrequent. Clinical symptoms were similar between the viral and the viralbacterial groups.

\section{Microbiological findings}

HRV was the only microbe detected in $12(60 \%)$ cases. The microbiological findings of bacterial-viral infection records are shown in Table 1. Streptococcus pneumoniae (3, 15\%), Klebsiella pneumoniae (3, 15\%) and Mycoplasma pneumoniae 


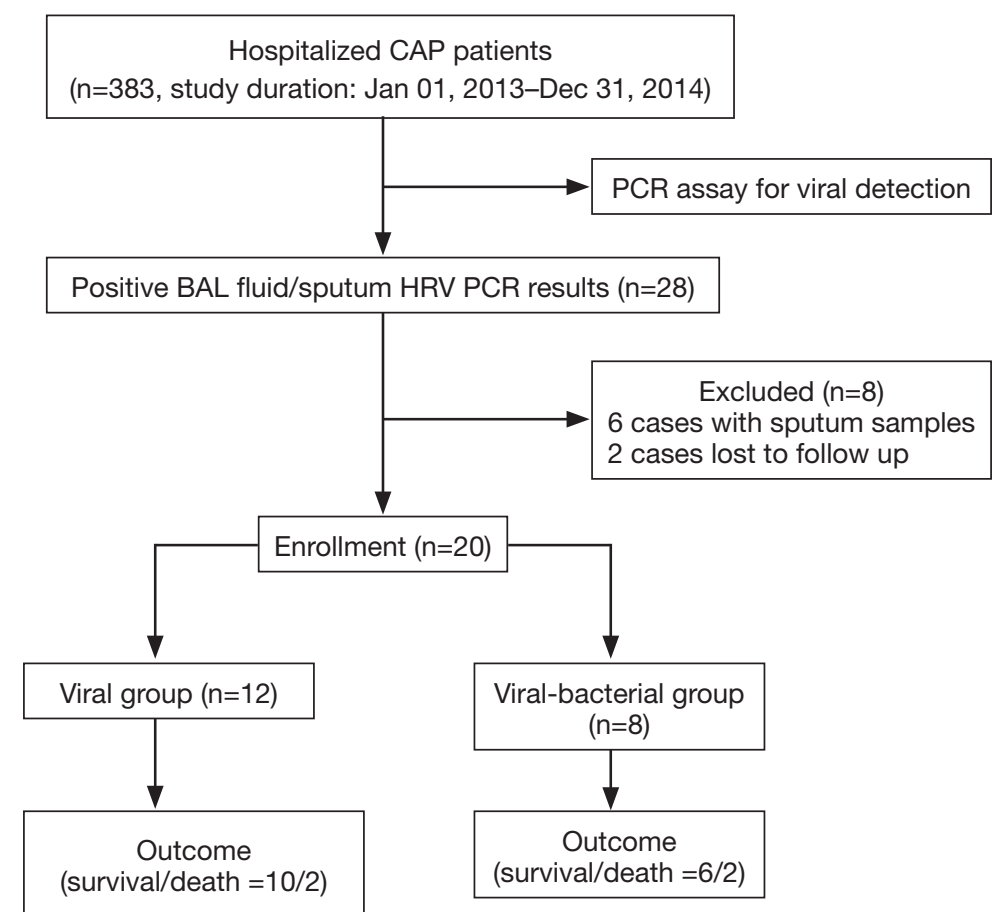

Figure 1 Flow chart of study inclusion process. CAP, community-acquired pneumonia; PCR, polymerase chain reaction; BAL, bronchoalveolar lavage; HRV, human rhinovirus; LAMP, loop-mediated isothermal amplification.

$(2,10 \%)$ were the most common bacterium identified in the study. Streptococcus pneumoniae and Klebsiella pneumoniae the most common combinations of bacterial dual infection observed. All patients in our series had actually received antibiotics before respiratory tract sampling.

\section{Laboratory findings}

The comparisons of laboratory findings for the groups (viral group and viral-bacterial group) are presented in Table 2. Oxygenation index $\left(\mathrm{PaO}_{2} / \mathrm{FiO}_{2}\right)$ was notably poor in both groups; the median value was $254 \mathrm{mmHg}$, and it was below $200 \mathrm{mmHg}$ in 6 cases (5 in the viral group and 1 in viral-bacterial group). Unlike other viral pneumonia, leukocytosis was observed with a median count of $11.2 \times 10^{9} / \mathrm{L}$, no matter with or without bacterial co-infection. Extremely high procalcitonin (PCT) levels $(>1.0 \mathrm{ng} / \mathrm{mL})$ were noted even in the viral group. However, we could not calculate the median value of PCT since the test was unavailable in some hospitals. The only statistically significant data between the two groups was the serum concentration of creatine kinase (CK), which was higher in the viral-bacterial group (318 vs. $41.4 \mathrm{U} / \mathrm{L}$, $\mathrm{P}=0.027)$. Neither obvious organ dysfunction nor severe electrolyte disturbance occurred in both groups.

\section{Imaging findings}

No specific patterns of pulmonary infiltration were noted in cases with HRV-associated pneumonia. Both diffuse patchy infiltrations and lobar consolidations were observed in the chest computed tomography (CT) images, as revealed in Figure 3. Pleural effusion revealed in five cases. There were no statistical differences between the two groups, as detailed in Table 2.

\section{Clinical outcomes}

Cases with HRV-infection were remarkably correlated with respiratory failure (14/20) and most of them (13/14) received mechanical ventilation. In Figure 2, we observed that the prevalence of SCAP in cases with HRV detection was as high as in cases without HRV-detection $(15 / 28$, $53.57 \%$ and $156 / 355,43.94 \%$, respectively, $\mathrm{P}=0.332$ ). And between the viral group and the viral-bacterial group, the rates of developing SCAP were $7 / 15$ (46.67\%) and 8/13 (61.54\%) respectively, $\mathrm{P}=0.476$. As demonstrated in Table 2, CAP patients in the viral group were more severely ill on admission, based on pneumonia severity index (PSI) and CURB-65 scores $(13,14)$. Respiratory failure $\left(\mathrm{PiO}_{2} /\right.$ $\mathrm{FiO}_{2}$ ratio $<300 \mathrm{mmHg}$ ) happened in 14 patients (9 in 
Table 1 Microbiological etiologies and baseline characteristics of study group

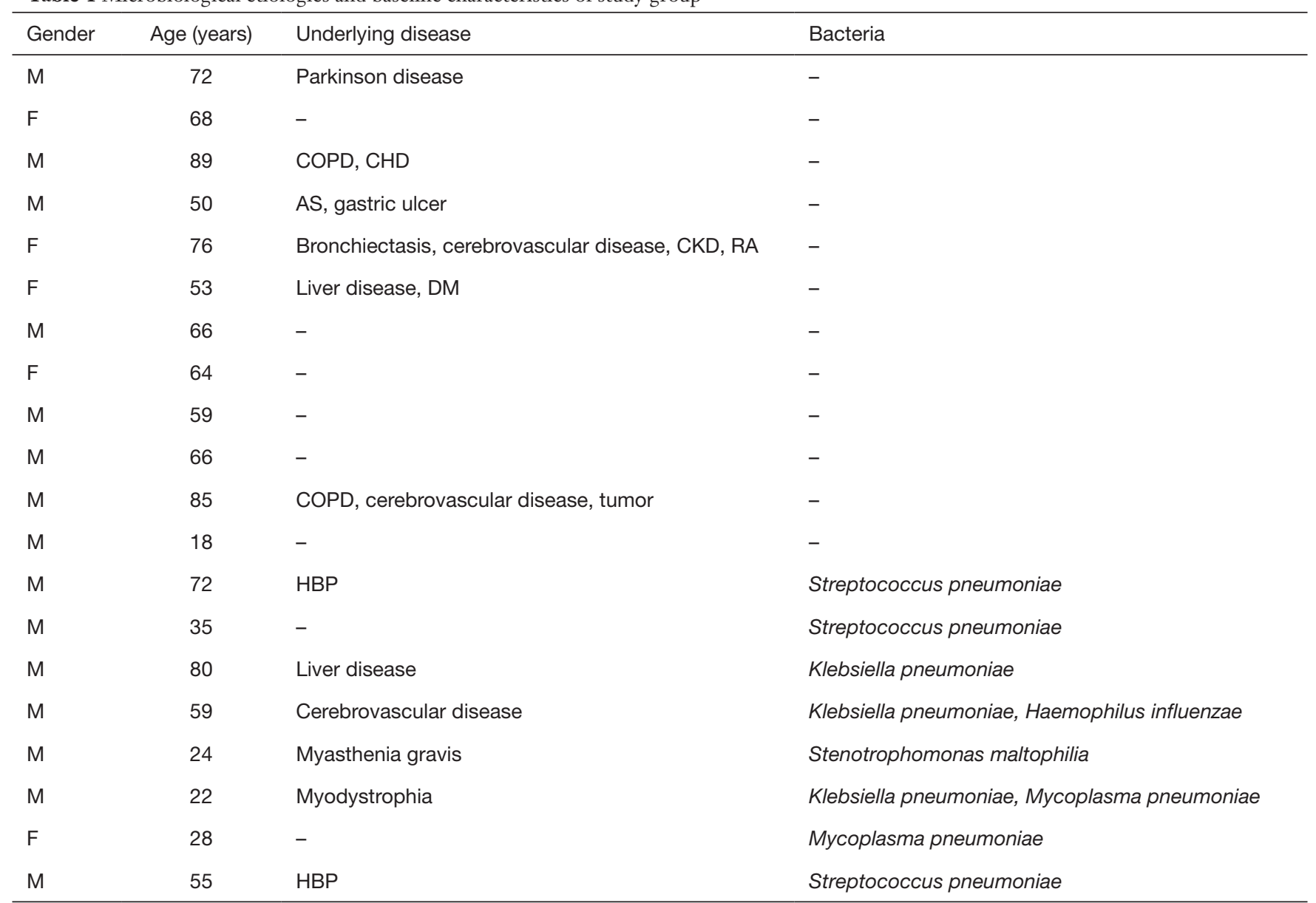

F, female; M, men; COPD, chronic obstructive pulmonary disease; AS, ankylosing spondylitis; CKD, chronic kidney disease; DM, diabetes mellitus; HBP, hypertension; RA, rheumatoid arthritis; CHD, coronary heart disease.

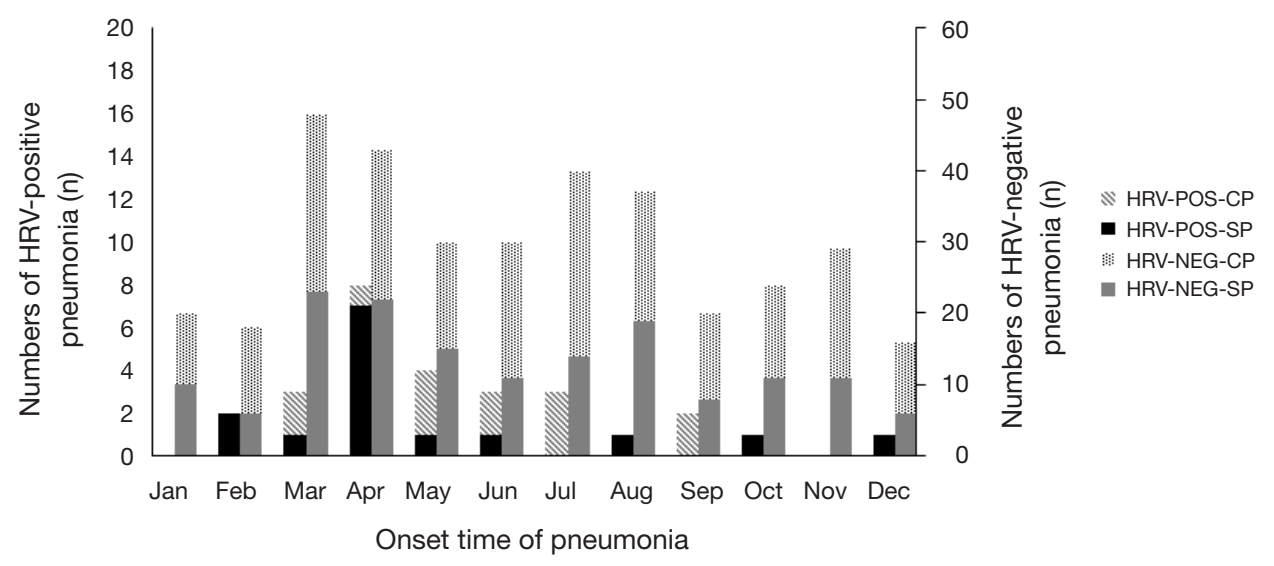

Figure 2 Distribution time of HRV detections. HRV, human rhinovirus; HRV-POS-CP, non-severe pneumonia with HRV positive detection; HRV-POS-SP, severe pneumonia with HRV positive detection; HRV-NEG-CP, non-severe pneumonia without HRV positive detection; HRV-NEG-SP, severe pneumonia without HRV positive detection. 
Table 2 Symptoms, physical findings, laboratory and clinical data on admission

\begin{tabular}{|c|c|c|c|}
\hline Characteristics & Viral group $(n=12)$ & Viral-bacterial group $(n=8)$ & $\mathrm{P}$ \\
\hline \multicolumn{4}{|l|}{ Symptoms and physical findings } \\
\hline Fever & 9 & 8 & 0.242 \\
\hline Productive cough & 8 & 7 & 0.603 \\
\hline Dyspnea & 3 & 3 & 0.642 \\
\hline Shiver & 1 & 1 & 1 \\
\hline Chest pain & 1 & 0 & 1 \\
\hline Diarrhea & 0 & 1 & 0.4 \\
\hline Headache & 1 & 0 & 1 \\
\hline Respiratory rate $(\mathrm{bpm})>30$ & 3 & 1 & 0.619 \\
\hline Temperature $\left({ }^{\circ} \mathrm{C}\right)$ [median (range)] & 38.7 (36.6-39.3) & $39.1(38.6-39.7)$ & 0.270 \\
\hline Heart rate (bpm) [median (range)] & 95 [87-105] & $105[100-111]$ & 0.157 \\
\hline \multicolumn{4}{|c|}{ Laboratory and clinical data [median (range)] } \\
\hline WBC $\left(\times 10^{9} / \mathrm{L}\right)$ & $11.2(6.7-15.2)$ & $10.63(8.5-17.2)$ & 0.678 \\
\hline Percentage of neutrophils (\%) & $83.6(78.7-91.5)$ & $87.6(83.1-92.9)$ & 0.343 \\
\hline ALT (U/L) & $19.1(12.9-33.5)$ & $47.3(19.3-53.5)$ & 0.062 \\
\hline AST (U/L) & $24.5(19.8-40)$ & $42.2(23.8-66.6)$ & 0.356 \\
\hline \multicolumn{4}{|l|}{ Radiologic findings } \\
\hline Bilateral involvement & 8 & 4 & 0.648 \\
\hline Unilateral involvement & 4 & 4 & \\
\hline Consolidation & 6 & 6 & 0.287 \\
\hline Diffuse infiltration & 3 & 2 & \\
\hline Pleural effusion & 4 & 1 & 0.603 \\
\hline
\end{tabular}

Table 2 (continued) 
Table 2 (continued)

\begin{tabular}{|c|c|c|c|}
\hline Characteristics & Viral group $(n=12)$ & Viral-bacterial group $(n=8)$ & $\mathrm{P}$ \\
\hline \multicolumn{4}{|l|}{ Admission parameters } \\
\hline CURB-65 $\geq 2$ & 5 & 3 & 0.851 \\
\hline \multicolumn{4}{|l|}{ PSI } \\
\hline$\leq 70$ & 3 & 3 & 0.642 \\
\hline $91-130$ & 6 & 1 & 0.158 \\
\hline$>130$ & 2 & 3 & 0.347 \\
\hline $\mathrm{P} / \mathrm{F}$ ratio [median (range)] & 255 [143-297] & 254 [240-415] & 0.343 \\
\hline$<300$ & 9 & 5 & 0.642 \\
\hline Noninvasive mechanical ventilation & 5 & 2 & 0.642 \\
\hline \multicolumn{4}{|l|}{ Clinical outcomes } \\
\hline Hospital stays (days) [median (range)] & $13.0(11.8-16.5)$ & $18.5(13.0-23.5)$ & 0.208 \\
\hline ICU stays (days) [median (range)] & $6.5(1.0-13.0)$ & $10.0(8.5-14)$ & 0.686 \\
\hline ICU mortality (\%) & $2 / 4(50.0)$ & $2 / 4(50.0)$ & 1 \\
\hline 28-day mortality (\%) & $2 / 12(12.5)$ & $2 / 8(25.0)$ & 1 \\
\hline Hospital mortality (\%) & $2 / 12(12.5)$ & $3 / 8(37.5)$ & 0.347 \\
\hline Ventilation failure (\%) & $1 / 2(50.0)$ & $3 / 4(75.0)$ & 0.412 \\
\hline
\end{tabular}

*, $\mathrm{P}<0.05$; , , data missing for 1 cases; ${ }^{\mathrm{b}}$, data missing for 2 cases; ${ }^{\mathrm{c}}$, data missing for 2 cases. WBC, white blood cell (normal range, 4-10×10\%/L); ALT, alanine aminotransferase (normal range, 9-40 U/L); AST, aspartate transaminase (normal range, 15-40 U/L); BUN, blood urea nitrogen (normal range, 2.8-7 $\mu \mathrm{mol} / \mathrm{L}$ ); CK, creatine kinase (normal range, 56-244 U/L); ESR, erythrocyte sedimentation rate (normal range, 0-20 mm/h); PSI, pneumonia severity index; $\mathrm{P} / \mathrm{F}$ ration, $\mathrm{PiO}_{2} / \mathrm{FiO}_{2}$ ratio (normal range, 300-500).

the viral group and 5 in viral-bacterial group, $\mathrm{P}=0.642$ ) and finally 13 out of them (92.9\%) were warranted for mechanical ventilation. Clinical deterioration was more common in viral-bacterial group compared to viral group; higher incidence of septic shock ( $3 / 8 v s .1 / 12, \mathrm{P}=0.255)$, longer ICU length of stay (LOS) (10.0 vs. 6.5 days, $\mathrm{P}=0.686)$, longer hospital LOS (18.5 vs. 13.0 days, $\mathrm{P}=0.208$ ) and higher 28 -day mortality ( $25 \%$ vs. $12.5 \%, \mathrm{P}=1)$ were observed, although without statistically significant difference.

\section{Discussion}

HRV, first discovered in the 1950s (15), is widely accepted as the most common etiology causing upper respiratory tract infections (URTIs), including common cold, acute otitis media, and rhino sinusitis (16). In recent years, researchers have found that $\mathrm{HRV}$-infection is also associated with acute exacerbations and prolonged hospitalizations of chronic obstructive pulmonary disease (16-18), asthma $(19,20)$, and cystic fibrosis (21). In addition, HRV has emerged as an important cause of pneumonia for its severity and poor prognosis in infants and children $(22,23)$. Furthermore, plenty of evidence strongly suggest that $\mathrm{HRV}$ is an independent causative agent in lower respiratory tract infections (LRTIs): HRV can replicate in both $33^{\circ} \mathrm{C}$ and $37^{\circ} \mathrm{C}$, the temperature of the upper and lower airway respectively (24); HRV can bind to ICAM-1 (Inter-Cellular Adhesion Molecule 1) receptors on bronchial epithelial cells (16); bronchial infection can be confirmed when exposing either primary human bronchial epithelial cells to rhinovirus in vitro or after exposing human volunteers to 

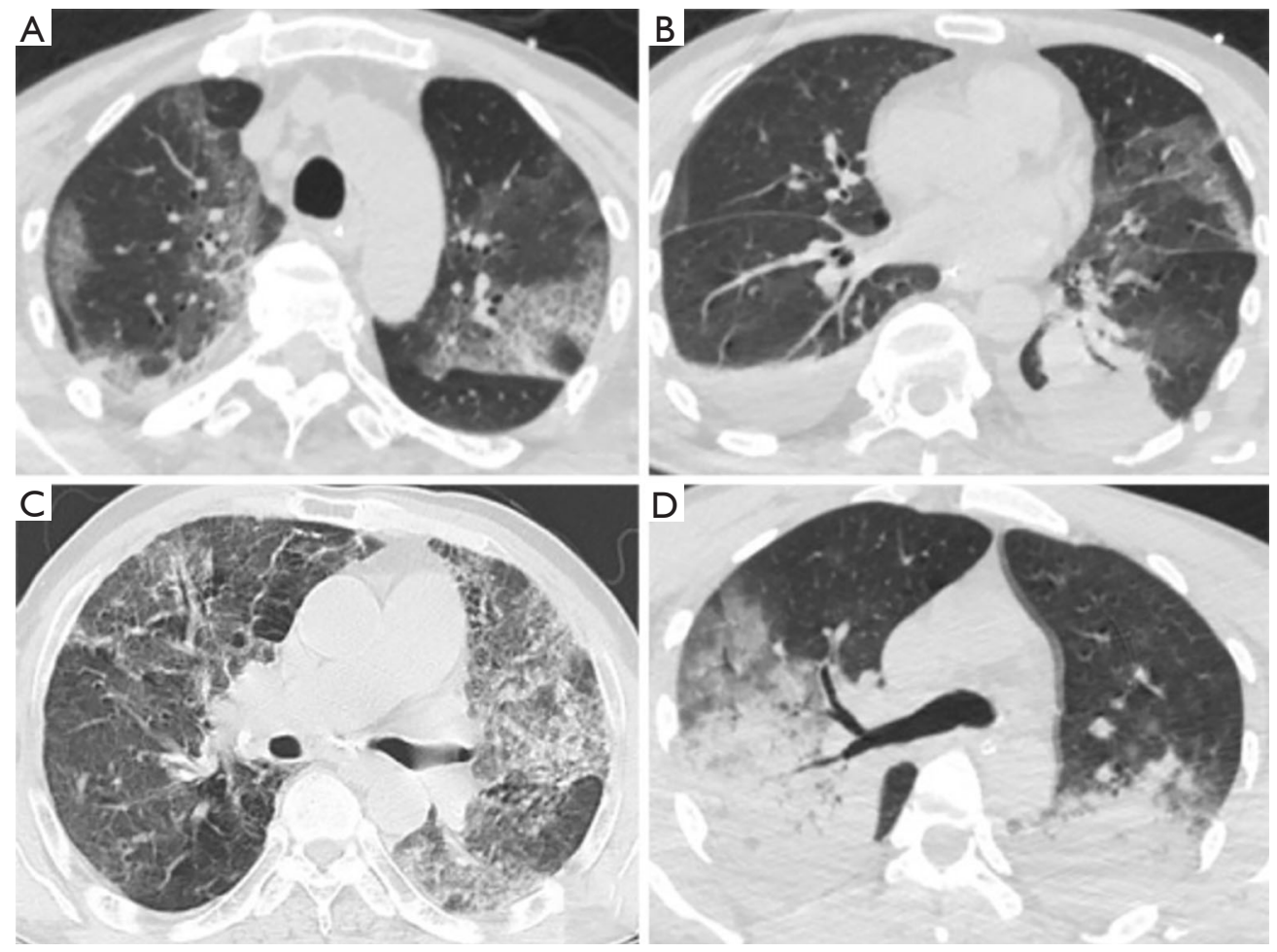

Figure 3 Chest CT images of HRV-CAP. (A,B) M/50 years old, SCAP, HRV-detected only. Diffuse patchy infiltrations, lobar consolidation, companied with bilateral pleural effusions were observed in his chest CT; (C) M/66 years old, CAP, HRV-detected only. CT showed bilateral diffuse ground grass opacities; (D) M/35 years old, SCAP, HRV-Streptococcus pneumoniae co-infection. CT revealed bilateral lobar consolidations. CAP, community-acquired pneumonia; SCAP, severe community-acquired pneumonia; CT, computed tomography; HRV, human rhinovirus.

experimental upper respiratory infection in vivo $(6,25)$.

However, the debate about the role of HRV in LRTIs is still ongoing, especially in immunocompetent individuals. So far, the majority of investigations about HRV-associated LRTIs in adults focus on the immunocompromised cases (26-29) or hospital-acquired pneumonia (HAP) $(30,31)$, which are indeed not able to present the natural scenarios. Alternatively, the samples analyzed in these studies are mostly sputum or nasopharyngeal swabs. As in a recent study of Jain et al. (32), although the positive rate is much lower in a healthy controls group compared to the CAP patients group, it is still controversial whether HRV is the causative etiology as they are spread easily through person-to-person contact $(16,33)$.

A major strength of our study was that HRV-infection was confirmed via BAL samples obtained from CAP patients, which certainly highlights the etiological importance of these findings. Furthermore, it was a prospective study conducted at multiple medical centers. Finally, despite the limited number of patients analyzed, this is the largest study with BAL PCR sampling of immunocompetent CAP patients thus far reported.

In this series, respiratory failure was remarkably common and 12 cases ( 7 in the viral group and 5 in the viral-bacteria group, $\mathrm{P}=0.612$ ) were classified into SCAP. No significant difference was observed in the prevalence of SCAP in the group with HRV-detection group and in the group without HRV-detection (Figure 2). The results indicated that HRV may have an essential role in the pathogenesis of SCAP, even in mono-infection. In addition, despite the viral group had higher clinical severity scores of pneumonias on admission, the viral-bacterial group turned out to have longer ICU LOS and hospital LOS, and worse clinical outcome. The result was consistent with former studies $(1,32,34)$. Polymicrobial infections in CAP are generally considered to cause more severe inflammation and tissue damage than single microbial infections as observed in our study, patients in the viral-bacterial group had more elevated CK than in the viral group. But it is still an open question 
whether the clinical manifestations are related directly to viral pathogenicity, or the viral infection just predisposes the patient to bacterial pneumonia, as observed in influenza virus pneumonia (35). Further studies need to be done to illustrate the underlying pathogenesis. Lastly, no special laboratory workup or particular patterns of radiographic changes were observed in HRV-associated pneumonia. Leukocytosis and elevated PCT were common even in the viral group, and pulmonary consolidation appeared in CT images with or without bacterial co-infection.

A potential weakness of this study was that patients enrolled were just hospitalized CAP cases, which could produce a selective bias towards more severely ill cases. The findings from this study only represent the situation of these CAP or SCAP patients and limit the generalizability of the results for other patients, especially patients with mild HRV infection. Furthermore, the relatively small sample size may affect the statistical analysis; for example, multivariate logistic regression analyses could not be calculated to identify risk factors for mortality. Least but not last, all patients received antimicrobial agents for more than 24 hours before hospital admission. Thus, some patients may have had false bacterial-negative findings, and the proportion of patients infected with respiratory viruses might have been overestimated.

\section{Conclusions}

In conclusion, HRV is a common etiology in CAP among China adults, SCAP particularly. Highly qualified multiplex PCR methods with invasive sampling can help to increase the detection rate. Clinicians should be vigilant considering of the poor outcome of HRV-associated CAP. Although specific antiviral agents for the treatment are not available, raised awareness of the severity and sufficient supportive treatment might help to improve the outcome.

\section{Acknowledgements}

Funding: The study was funded by the Ministry of Science and Technology of China (grant number 2012ZX10004-206) and the National Health and Family Planning Commission of China (grant number 2016YFC0903800).

\section{Footnote}

Conflicts of Interest: The authors have no conflicts of interest to declare.
Ethical Statement: The study was approved by the Ethics Committee of Peking University People's Hospital (No. 2011-83), and written informed consent was obtained from all patients.

\section{References}

1. Templeton KE, Scheltinga SA, van den Eeden WC, et al. Improved diagnosis of the etiology of community-acquired pneumonia with real-time polymerase chain reaction. Clin Infect Dis 2005;41:345-51.

2. Karhu J, Ala-Kokko TI, Vuorinen T, et al. Lower respiratory tract virus findings in mechanically ventilated patients with severe community-acquired pneumonia. Clin Infect Dis 2014;59:62-70.

3. Jennings LC, Anderson TP, Beynon KA, et al. Incidence and characteristics of viral community-acquired pneumonia in adults. Thorax 2008;63:42-8.

4. Johansson N, Kalin M, Tiveljung-Lindell A, et al. Etiology of community-acquired pneumonia: increased microbiological yield with new diagnostic methods. Clin Infect Dis 2010;50:202-9.

5. Lieberman D, Shimoni A, Shemer-Avni Y, et al. Respiratory viruses in adults with community-acquired pneumonia. Chest 2010;138:811-6.

6. Johnston SL. Natural and experimental rhinovirus infections of the lower respiratory tract. Am J Respir Crit Care Med 1995;152:S46-52.

7. Fuji N, Suzuki A, Lupisan S, et al. Detection of human rhinovirus $\mathrm{C}$ viral genome in blood among children with severe respiratory infections in the Philippines. PLoS One 2011;6:e27247.

8. Chidekel AS, Bazzy AR, Rosen CL. Rhinovirus infection associated with severe lower respiratory tract illness and worsening lung disease in infants with bronchopulmonary dysplasia. Pediatr Pulmonol 1994;18:261-3.

9. Mandell LA, Wunderink RG, Anzueto A, et al. Infectious Diseases Society of America/American Thoracic Society consensus guidelines on the management of community-acquired pneumonia in adults. Clin Infect Dis 2007;44:S27-S72.

10. Sakthivel SK, Whitaker B, Lu X, et al. Comparison of fast-track diagnostics respiratory pathogens multiplex realtime RT-PCR assay with in-house singleplex assays for comprehensive detection of human respiratory viruses. J Virol Methods 2012;185:259-66.

11. Chen Y, Wang D, Li H, et al. The application of loopmediated isothermal amplification for detection of 
common pathogenic bacteria in lower respiratory tract infections. Zhonghua Jie He He Hu Xi Za Zhi 2014;37:270-3.

12. Kang Y, Deng R, Wang C, et al. Etiologic diagnosis of lower respiratory tract bacterial infections using sputum samples and quantitative loop-mediated isothermal amplification. PloS One 2012;7:e38743.

13. Fine MJ, Auble TE, Yealy DM, et al. A Prediction Rule to Identify Low-Risk Patients with Community-Acquired Pneumonia. N Engl J Med 1997;336:243-50.

14. Capelastegui A, Espana P, Quintana J, et al. Validation of a predictive rule for the management of communityacquired pneumonia. Eur Respir J 2006;27:151-7.

15. Price $W H$. The isolation of a new virus associated with respiratory clinical disease in humans. Proc Natl Acad Sci U S A 1956;42:892-6.

16. Jacobs SE, Lamson DM, St George K, et al. Human rhinoviruses. Clin Microbiol Rev 2013;26:135-62.

17. George SN, Garcha DS, Mackay AJ, et al. Human rhinovirus infection during naturally occurring COPD exacerbations. Eur Respir J 2014;44:87-96.

18. Gandhi A, Walsh EE, Formica MA, et al. Factors associated with symptomatic rhinovirus infection in patients with COPD. J Clin Virol 2012;55:343-7.

19. Kloepfer KM, Lee WM, Pappas TE, et al. Detection of pathogenic bacteria during rhinovirus infection is associated with increased respiratory symptoms and asthma exacerbations. J Allergy Clin Immunol 2014;133:1301-7. e3.

20. Teichtahl H, Buckmaster N, Pertnikovs E. The incidence of respiratory tract infection in adults requiring hospitalization for asthma. Chest 1997;112:591-6.

21. Flight WG, Bright-Thomas RJ, Tilston P, et al. Chronic rhinovirus infection in an adult with cystic fibrosis. J Clin Microbiol 2013;51:3893-6.

22. Juvén T, Mertsola J, Waris M, et al. Etiology of community-acquired pneumonia in 254 hospitalized children. Pediatr Infect Dis J 2000;19:293-8.

23. McIntosh K. Community-acquired pneumonia in children. N Engl J Med 2002;346:429-37.

Cite this article as: Wang $\mathrm{K}$, Xi W, Yang D, Zheng Y, Zhang Y, Chen Y, Yan C, Tian G, An S, Li X, An F, Du J, Hu K, Cao J, Ren L, Huang F, Gao Z. Rhinovirus is associated with severe adult community-acquired pneumonia in China. J Thorac Dis 2017;9(11):4502-4511. doi: 10.21037/jtd.2017.10.107
24. Papadopoulos NG, Sanderson G, Hunter J, et al. Rhinoviruses replicate effectively at lower airway temperatures. J Med Virol 1999;58:100-4.

25. Papadopoulos NG, Bates PJ, Bardin PG, et al. Rhinoviruses infect the lower airways. J Infect Dis 2000;181:1875-84.

26. Costa C, Bergallo M, Astegiano S, et al. Detection of human rhinoviruses in the lower respiratory tract of lung transplant recipients. Arch Virol 2011;156:1439-43.

27. Hicks LA, Shepard CW, Britz PH, et al. Two outbreaks of severe respiratory disease in nursing homes associated with rhinovirus. J Am Geriatr Soc 2006;54:284-9.

28. Ison MG, Hayden FG, Kaiser L, et al. Rhinovirus infections in hematopoietic stem cell transplant recipients with pneumonia. Clin Infect Dis 2003;36:1139-43.

29. Mikulska M, Del Bono V, Gandolfo N, et al. Epidemiology of viral respiratory tract infections in an outpatient haematology facility. Ann Hematol 2014;93:669-76.

30. Louie JK, Yagi S, Nelson FA, et al. Rhinovirus outbreak in a long term care facility for elderly persons associated with unusually high mortality. Clin Infect Dis 2005;41:262-5

31. Wald TG, Shult P, Krause P, et al. A rhinovirus outbreak among residents of a long-term care facility. Ann Intern Med 1995;123:588-93.

32. Jain S, Self WH, Wunderink RG, et al. CommunityAcquired Pneumonia Requiring Hospitalization among U.S. Adults. N Engl J Med 2015;373:415-27.

33. Gwaltney JM Jr, Moskalski PB, Hendley JO. Hand-tohand transmission of rhinovirus colds. Ann Intern Med 1978;88:463-7.

34. Choi SH, Huh JW, Hong SB, et al. Clinical characteristics and outcomes of severe rhinovirus-associated pneumonia identified by bronchoscopic bronchoalveolar lavage in adults: Comparison with severe influenza virus-associated pneumonia. J Clin Virol 2015;62:41-7.

35. Lee LN, Dias P, Han D, et al. A mouse model of lethal synergism between influenza virus and Haemophilus influenzae. Am J Pathol 2010;176:800-11. 